\title{
MEANS OF MASS COMMUNICATION AND THE POSSIBILITY OF MONITORING THE ELEMENTS OF FOLKLORE UNDER THE AXIS: THE ROLE OF THE MEDIA IN SUSTAINABLE DEVELOPMENT \\ Walaa Muhammad MAHMOUD * \\ Academy of Arts, Higher Institute of Folk Art, Egypt
}

\begin{abstract}
The media has a role in documenting heritage and displaying its vocabulary, as it sets the cornerstone for influencing society and shaping its identity among societies as a whole, especially the mass media in all its forms. It plays this role, regardless of the variety and diversity of mass communication media, with its multiplicity of newspapers, magazines, television, cinema and other means, whether from By displaying the still photographic image in newspapers and magazines or the moving image in television and cinema. All these means have a realistic, influential and disciplined role in presenting the documented heritage supported with complete information. The image has a strong role in displaying and sending the informational message, that is, the medium is the most important and most used of the human senses.

Keywords

Means of Mass Communication, Monitoring, Folklore, Media, Sustainable Development.
\end{abstract}

\section{Introduction}

the power of the image stems from the concept of ratification and denial, because visual vision is the basis of validation, and the importance of the image lies in its ability to address the learner, the illiterate, the old and the young, the image differs from the spoken or written word in that it breaks the barrier of languages and dialects, so it is the most widespread, and the image is related to something tangible And it is tangible and specific, and it is the dimensions of the image, and it differs from the written word in the ease of reception, because reading requires contemplation and preoccupation of the mind, and the picture does not need a great mental effort to receive it, the picture is worth a thousand words, and it displays peoples cultures and minds of millions with flowing information, showing a film comparable to reading several books.

Heritage topics from folk literature, whether it is poetry or story and folk art from wall drawings, as well as material culture and the folk crafts that it contains such as ceramics, weaving, kilims, wicker and others, in addition to folk performance arts that display dance, music and folk singing, customs and beliefs of peoples must be presented. And such topics are presented within the media optimally by setting up a working mechanism based on preserving the popular tradition because of its distinctive peculiarity to highlight the identity of the society in which we are about to live, in addition to working on developing the maxim to preserve it

*Corresponding author: info@academyofarts.edu.eg 
from distortion, distortion and external invasion.

That the coming invasion is an intellectual media invasion in which the colonizer invades the mind, ideas and identity, and thus affects the heritage of countries and makes them lose their distinction.

Benefiting from the media, recognizing its negative aspects and developing its positives, will make us take confident steps towards a better society that does not forget its past, believes in its present and develops its future through the way to benefit from its generous proverbs with tight controls and high oversight that are free from flatness and have an in-depth, insightful view within our society.

In order to study the role of mass communication means in monitoring folklore elements:

1- What is mass communication and its components.

2- Mass communication methods used to monitor elements of folklore.

3- Characteristics of mass communication and how it is successful in the monitoring process.

4- Results and recommendations that serve the idea of successful monitoring of the communication process.

\section{Mass Communication:}

It is a communication process that takes place using mass media that are characterized by their ability to deliver messages to a wide and dispersed audience.

\section{Elements of Mass Communication:}

\section{One of the first elements of mass communication is:}

1- The sender: $\mathrm{He}$ is the one who sends the information and ideas that he wants to communicate to the masses, whatever their type, and by the means through which the sender can deliver the information according to his directions, ideas, preferences, culture, method of presentation, and the sender with regard to written mass communication means such as newspapers, books and magazines is the writer, author or journalist Depending on the nature of the medium, or a broadcaster, if it is a program or an actor, director, screenwriter, and a dramatic or cinematic author, if the medium is a television drama or a movie.

2- The future: It is the one who receives the information that is presented or what is called the audience. The type of audience differs according to the target group, whether they are adults, young learners, religious illiterates or otherwise, and their religion, culture, social environment, intellectual, psychological and scientific development, and their willingness to receive and what is the nature of the means that they have Receive information from it and what is the degree of their assimilation of this information.

3- The message: It is the heritage information that the medium is about to display, express, 
draw attention to, classify it within the communication process, and present it in an effective way that serves the communication process and gives the desired result from this presentation. 4- The means: It is the nature of the presented material. Is it from reality as it is without the additions of the author, author or narrator, as happens in scientific books dealing with folklore topics. As for it part of it is subject to the author's imagination as it happens in novels quoted on subjects of folklore, or topics considered Press reports or news about events such as in magazines and newspapers, or information contained within cinematic films. Or the director.

5 - echo return: It is the feedback or result that appears through the viewable topic.

6- Interference: such as electronic interference that obstructs the message, or semantic interference in the construction of the message itself.

7- Impact: It is the result of communication, whether psychological or social.

8- Communication environment or context: It is the social, political or cultural conditions in which the communication takes place.

\section{In order for the mass communication process to take place in an optimal manner, basic} conditions must be met:

In order for it to flourish and develop in any society, and among these conditions is the existence of a solid economic base of financing necessary to obtain communication technology, such as printing houses, radio and television stations and broadcasting for the radio, the existence of a scientific and cultural base in society so that it can produce, distribute and consume information, and this includes increasing education between Members of the Society.

\section{Features and characteristics of cinema as a means of mass communication:}

- She does not need to watch her films to learn to read and write, so the educated, educated and others can watch and listen to them, bearing in mind that the more educated a person is, the more able to understand and educate.

Cinema employs movement, sound, color, and sound and non-vocal effects to influence the human being because it addresses the senses such as hearing, sight and heart.

- The individual goes to the cinema with his mind ready to enjoy the film and accept its content, and thus cinema provides a great opportunity for influence that no other means enjoy.

The cinema employs the ability to enlarge small scenes or small things and focus on them and bring them closer to the eye and mind of the viewer in a way that his eyes may not be able to. - Shedding light on the influence of the supportive mind in linking values and symbols with the connotations and meanings implicit in designing the corporate identity; And then enhancing the sensory experiences and consolidating the mental image of the recipient.

Employing the enhancement of the physical properties in the design or reformulating them to 
add new plastic dimensions; Which reflects positively on creating different creative ideas with both aesthetic and functional values.

Although cinema is considered one of the means of mass communication, its nature is dominated by entertainment and the presentation of humanitarian issues in an entertaining manner.

Most of the cinema subject matter is human issues in general. The viewer lives with the events of the film and merges with them and may be affected by them greatly.

9- Radio: Radio is one of the means of mass communication that can serve the topics of folklore through broadcast programs, which are audio recordings by experts and specialists who broadcast programs that deal with the heritage elements of customs, beliefs, folk celebrations or folk trades and monitor all of that. Via voice information by those interested.

\section{Advantages and characteristics of radio as a means of mass communication:}

the wide spread, the radio is one of the means of communication that can reach the entire population secretly bypassing all barriers, as it reaches special groups such as children, the elderly, the educated, the less educated and other groups that are difficult to reach by the media Other.

- The high speed with which the communication message is transmitted from the transmitter to the receiver. The communication via the radio does not need an intermediary, as it is delivered directly from the radio communicator to the listener.

- The radio does not need any effort on the part of the listeners, and as the majority of people become busy and do not have time to read or watch, the radio is the easy way to protect them from being aware of what is happening.

- The broadcast message may be stronger than the message conveyed by face-to-face communication, as the broadcast message can be strengthened with music and sound effects that leave a special impression on the listeners. Experiments have confirmed that simple materials presented through the radio are easier to remember than if they were presented in a special publication among less educated or intelligent individuals.

- The cheapness of radios, their low consumption of electricity, the possibility of operating them with dry batteries, and making them the most widespread in all parts of the world, especially in isolated islands, mountain peaks, modest dwellings and battlefields, where there are people most in need of culture, science and entertainment.

- The radio speaks to the ear, and thus it delights the sense, and works to stimulate and develop the imagination, and then it is one of the essential essential elements in the process of learning, raising awareness and developing personality. It was said in the past: The ear loves before the 
eye sometimes. "The radio suffers from one simple flaw, which is that the ease of use makes many deal with it without interest or focus, and thus the radio turns into a mere entertainment background rather than a platform for awareness and enlightenment, and the role of radio has declined after the invention of Television, and this decline increased after the tremendous developments in satellites and satellite channels

\section{0- Internet:}

The Internet is one of the important mass communication methods that display and combine various types of communication, cinema, television, radio, and documented written information. These means come together to enter the Internet as one specific unit that displays these means according to the circumstances, events, attitudes and interests that draw the attention of the target audience, attract attention and create a kind of Standing on this method as one of the most important means of mass communication that transcends the limits of time and place and what is displayed on the Internet and expresses all of that varies between programs that deal with one of these means or all together, such as Facebook and Instagram programs, programs that display books and other social media programs that It is concerned with presenting the field and scientific material for the elements of folklore

\section{The distinct role of all kinds of images in monitoring folklore elements:}

The means of mass communication depend heavily on the image, whether this image is fixed or moving. The image has a strong role in displaying and sending the media message, as vision is the most important and most used human senses in acquiring information.

And the strength of the image stems from the concept of ratification and denial, because visual vision is the basis of certification, and the importance of the image lies in its ability to address the learner, the illiterate, the old and the young, the image differs from the spoken or written word in that it breaks the barrier of languages and dialects, and the image is related to something tangible, tangible and specific, which are dimensions The picture differs from the written word in the ease of reception, because reading requires contemplation and preoccupation with the mind, and the picture does not require a great mental effort to receive it, so the picture is worth a thousand words, and it displays peoples' cultures and invades the minds of millions with flowing information, so presenting a film is comparable to reading several books.

\section{Examples of pictures that express various elements of folklore:}

Pictures expressing popular professions such as rosary salesman in front of mosques as in Picture No. (21), so the presentation of the popular element expressing the aesthetic and artistic formation is evident through the direction of the seller's gaze, the way he leans on the ground, the clothes he wears, the tools he uses, the way he displays the rosaries, and the people sitting 
around Place in general and organize it in a long shot.

\section{References}

- Mirette Gamal Kamil MOAWAD, Nagwa Yahya EL-ADAWY, Dina ABBOUD, A CONCEPTUAL FRAMEWORK FOR THE SCAFFOLDED MIND AND ITS INFLUENCE ON ENHANCING MULTISENSORYEXPERIENCE IN CORPORATE IDENTITY, International Journal of Humanities and Language Research, Vol. 1, No. 1, 2018, pp. 1-15.

- Mona Abdel-Rahim ADLY, CHOREOGRAPHIC COMPOSITIONS AND THEIR PERFORMANCE BY HERBERT HOWELLS, International Journal of Humanities and Language Research, Vol. 1, No. 1, 2018, pp. 16-23.

Received: August 13, 2018

Accepted: October 21, 2018 